Jul 1st, 12:00 AM

\title{
Drought Mitigation using Operative Indicators in Complex Water Systems
}

Giovanni M. Sechi

Andrea Sulis

Follow this and additional works at: https://scholarsarchive.byu.edu/iemssconference

Sechi, Giovanni M. and Sulis, Andrea, "Drought Mitigation using Operative Indicators in Complex Water Systems" (2008).

International Congress on Environmental Modelling and Software. 205.

https://scholarsarchive.byu.edu/iemssconference/2008/all/205

This Event is brought to you for free and open access by the Civil and Environmental Engineering at BYU ScholarsArchive. It has been accepted for inclusion in International Congress on Environmental Modelling and Software by an authorized administrator of BYU ScholarsArchive. For more information, please contact scholarsarchive@byu.edu, ellen_amatangelo@byu.edu. 


\title{
Drought Mitigation using Operative Indicators in Complex Water Systems
}

\author{
G.M. Sechi ${ }^{\mathrm{a}}$ and $\underline{\mathrm{A} . \text { Sulis }^{\mathrm{b}}}$ \\ ${ }^{a}$ Hydraulic Sector, Dept. of Land Engineering, University of Cagliari, Italy \\ (sechi@unica.it) \\ ${ }^{b}$ Hydraulic Sector, Dept. of Land Engineering, University of Cagliari, Italy \\ (asulis@unica.it)
}

\begin{abstract}
The definition of an effective link between drought indicators and drought mitigation measures in complex water systems is a tricky problem. In our view this gap between research and practice still limits the applicability of measures more than institutional or technological aspects. In this paper a methodology is presented with the aim of supporting water Authorities in the decision making process to face droughts in complex water systems. The methodology is a full integration of optimization and simulation tools. The exploratory power of the optimization allows to fast estimate drought risk indicators under future hydrological scenarios. The optimization model uses these indicators as triggers of measures in a pro-active approach. Then, a more robust and detailed simulation is used to test and evaluate these set of measures. Particularly in the case of too optimistic hydrological forecast, the pro-active approach does not completely eliminate the risk of drought and further measures in a reactive approach have to be implemented in the simulation. They include expensive and big impact measures to be taken later, during the drought event. Thanks to the collaboration with the regional water Authorities in South Italy, the proposed methodology has been currently under test in the Agri-Sinni water system. Early applications to the Agri-Sinni water system are presented in the paper showing the usefulness of the proposed methodology in mitigating the impacts of drought and selecting an economic efficient combination of pro-active and reactive measures.
\end{abstract}

Keywords: Drought; Pro-active Measures; Complex Water Systems; Operating Rules; WARGI

\section{INTRODUCTION}

Particularly in water resource systems that frequently experience severe drought events, the definition of drought mitigation measures becomes a central aspect in the systems planning and management. Even if the usual approach is still to manage the water emergencies rather than to prevent them through a set of measures coherently developed in a pro-active approach, it seems that something is changing in legal and institutional framework. At this time, in our view a practical application of mitigation measures to complex water systems is limited by a nebulous link between these measures and drought indicators.

Different water system state indicators could be used as a trigger to start measures. For example, the reservoir storages or the total available water (reservoir storage plus inflow) measured in key reservoirs at the end of the wet season shall trigger the implementation of measures in systems where supplies come from superficial reservoirs. Nevertheless, the traditional approach requires to use iteratively a simulation model to define a monthly probability distribution of satisfying predefined demand scenarios (or level of alert) based on the current values of drought indicators in the system. At times the definition of this matrix of probabilities can be long and difficult, and a high number of potential 
combinations have to be compared. Also, in this approach mitigation measures are statically implemented as each demand scenario contains itself a set of measures to satisfy the demand. When the matrix is defined, simulation model is then used to test the time and the level of alert to be declared.

To improve the definition of an effective link between drought indicators and drought mitigation measures in complex water systems, a full integration of the simulation model WARGI-SIM (Water Resources Graphical Interface - Simulation Tool) and the linear optimization model WARGI-OPT has been recently developed (Sechi and Sulis, 2007) with the aim of identify and evaluate mitigation measures in a proactive approach that anticipate drought impacts. The pro-active approach includes measures implemented prior to the drought event with the aim of reducing the system vulnerability. Yevjevich et al. (1978) classified drought mitigation measures in three main categories: supply-oriented measures, demand-oriented measures and impact-minimization measures. While the impact-minimization measures are basically related to water users and various factors, which can minimize the economic, environmental and social impacts, supply and oriented demand measures are intended to reduce the risk of water scarcity. The mixed optimization-simulation approach aims to implement these two categories of measures (supply-oriented measures and demand-oriented measures) in a proactive approach considering a predefined infrastructural configuration of the water system.

In Sechi and Sulis (2007) the mixed optimization-simulation approach has been presented and applied to the South Sardinia (Italy) water system. Thanks to the regional water Authorities collaboration within a national research project (PRIN, 2005), the proposed approach has been currently under test in the Agri-Sinni (Southern Italy) water system. Preliminary results of the application to this complex water system are presented in the paper. The Agri-Sinni is a multireservoir and multiuse system that has frequently experienced extreme drought events in last decades. Results prove the usefulness of this approach in supporting water Authorities in the decision making process to face droughts in complex water systems.

\section{OPTIMIZATION AND SIMULATION APPROACH}

Despite difficulties in expressing all the system operations and constraints in a mathematical form, WARGI-OPT views the entire system as a single problem in time and space. This exploratory power of the optimization allows to dynamically defining a set of mitigation measures under different future hydrological scenarios. Then, WARGI-SIM is used to test and evaluate these set of measures. Particularly in the case of too optimistic hydrological forecast, the pro-active approach does not completely eliminate the risk of drought and measures in a reactive approach have also to be implemented in the simulation. The reactive approach includes more expensive and strong impact measures to be taken later, during the drought event, without reducing the system's vulnerability to future drought events. The effectiveness of these temporary actions may vary with the measures already implemented in the pro-active approach.

\subsection{Pro-active measures in the mixed optimization-simulation approach}

In the analysis of a water system on a time horizon $T$ with a time step $t$ (Figure 1), at each synchronization period $\tau_{i}$ in the simulation process, WARGI-OPT forecasts system evolution on a time horizon $\Delta$ based on current water storages in the system's reservoirs and a user-selected future hydrological synthetic scenarios. When dealing with hydrological uncertainty, the deterministic optimization method in WARGI-OPT can be implemented implicit stochastic environment (Hiew et al., 1989) with equally likely future hydrological scenarios. 
WARGI-SIM uses the information provided by WARGI-OPT at each synchronization period $\tau_{i}$ as triggers of mitigation measures in a pro-active approach $\left(\left[z_{\tau}\right]\right)$. These preemptive measures can modify system management in the subsequent periods until $\tau_{i+1}$. As well known, the simulation time horizon $T$ should be extended several decades in order to obtain a correct estimation of system performance.

The definition of the optimization time horizon $\Delta$, as well as the hydrological scenario weight, and costs or penalties associated with pre-emptive measures are key aspects in the approach

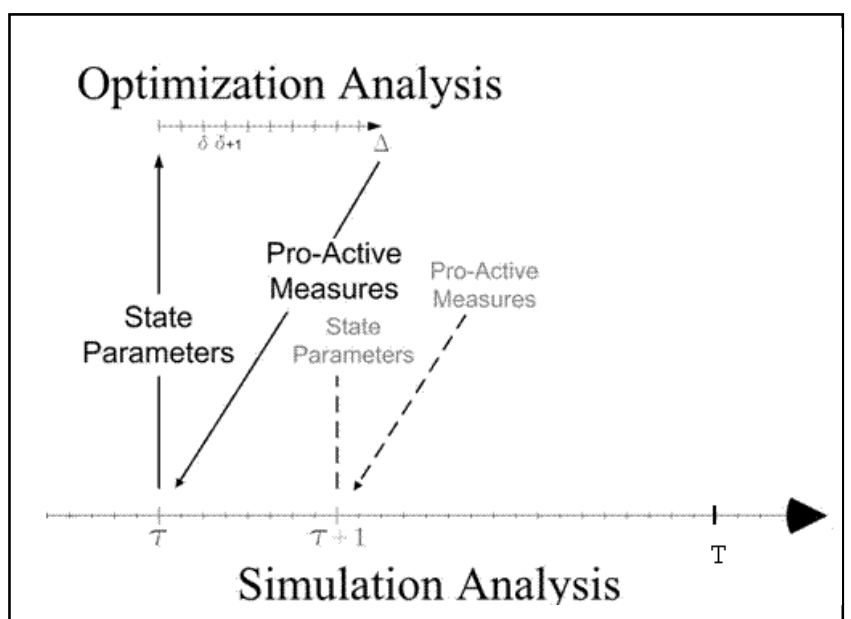

Figure 1. The optimization-simulation approach proposed (Sechi and Sulis, 2007).

\subsection{Reactive measures in the simulation model}

When pre-emptive measures $\left[z_{\tau}\right]$ do not make it possible to overcome the water scarcity in the simulation phase, WARGI-SIM introduces mitigation measures in a reactive approach $\left(\left[s_{t}\right]\right)$. Unlike other simulation models designed to describe system behaviour using complex specific algorithm rules embedded in the code, WARGI-SIM defines reactive measures $\left[s_{t}\right]$ based on preferences and priorities (Sechi and Sulis, 2007). For each strategic reservoir, the user defines a reserved volume as a function of the period of the year. When storage volume is within the reserved zone, downstream flows are decreased to satisfy few demands only. Strategic reservoirs and priority demands are selected by the user. In such cases, based on a hierarchical list of combination of resources and demands supply flows could be activated to meet non priority demands from alternative or marginal resources, or temporary restrictions could limit some non essential uses in these demands.

\subsection{Response function in the mixed approach}

The goal of the proposed approach is to define the best combination of drought mitigation measures that minimize the response function $R$. In the mixed optimization and simulation approach, $R$ can be written as the sum of costs associated to systems planning, OMR (operative, maintenance and replace costs) and mitigation measures:

$R=C_{\gamma} Y+\sum_{\tau_{i}} C_{P D} z_{\tau}+\sum_{t=1}^{T} C_{N P D} S_{t}+\sum_{t=1}^{T} \min \left(C_{O M R} x_{t}\right)$

The set $[z]_{\tau}$ represents drought mitigation measures in a proactive approach obtained by the WARGI-OPT. Particularly in the case of water scarcities more severe than those forecasted by WARGI-OPT, the response function $R$ includes measures $\left[s_{t}\right]$ in a reactive approach. The set of costs $\left[C_{\nu}\right]$ is related in the simulation to project variables $[Y]$ as defined by WARGI-OPT. $\left[C_{O M R}\right]$ represents operative, maintenance and replace costs, associated with flow variables $\left[x_{i}\right] .\left[x_{i}\right]$ is the solution of a minimum cost flow problem between resource and demand nodes in WARGI-SIM. $\left[C_{P D}\right]$ and $\left[C_{N P D}\right]$ are costs respectively associated with drought mitigation measures in a proactive and reactive approach. $\left[C_{P D}\right]$ and $\left[C_{N P D}\right]$ include OMR costs for drought measures, agency income lost from reduced water sales, and reduced consumer surplus due to these measures. 
The consumer surplus has been estimated by the willingness to pay method (Lund, 1995). When supply is less than users' maximum water demand, the consequent loss in total benefit value is given by the following integral formula (James and Lee, 1971):

$$
D=\int_{Q_{r}}^{Q_{s}} P_{s} \cdot\left(\frac{Q_{s}}{Q}\right)^{\frac{1}{E}} d Q
$$

where $Q_{s}$ indicates request for complete demand satisfaction, $P_{s}$ the resource's marginal cost under conditions of completely fulfilled demand, $Q_{r}$ reduced supply during the drought period, $E$ the price elasticity of demand. Clearly, $E$ is very low for demands in high priority (e.g. urban uses), where demand varies only slightly in relation to price; also, the value of elasticity in a short-term demand curve is lower than that in a long-term demand curve. Seasonal effects on water demand are not included in this approach.

\section{APPLICATION TO THE AGRI-SINNI WATER SYSTEM}

The Agri-Sinni water system (Figure 2) is located in Basilicata (South Italy) supplying demands also in Puglia and Calabria. The main reservoirs are Monte Cotugno (capacity of $556 \cdot 10^{6} \mathrm{~m}^{3}$ ) and Persusillo (capacity of $159 \cdot 10^{6} \mathrm{~m}^{3}$ ) along the Sinni and Agri River respectively. Marsico Nuovo and Cogliandrino are single purpose reservoirs (respectively for irrigation and hydroelectric use) with small regulation capacities. Four intake structures (Agri, Sarmento, Sauro and Gannano) were constructed on the main rivers for diversion of water.

Based on the observed monthly inflows at Monte Cotugno and Pertusillo over the period 19832005 , inflows in the other sections of interest in the basin were generated. Inflows series reproduce the intense water scarcities in the AgriSinni that occurred in the period 1989-1990 and 2001-2002. Table 1 shows the main properties of the series.

Urban, industrial (ILVA in Figure 2) and irrigation demands (C.B. in Figure 2) are respectively $246.5 \cdot 10^{6} \mathrm{~m}^{3} / \mathrm{yr}, 12.6 \cdot 10^{6}$ $\mathrm{m}^{3} / \mathrm{yr}$, and $240 \cdot 10^{6} \mathrm{~m}^{3} / \mathrm{yr}$.

The Agri-Sinni is a system often affected by intense water scarcities. Figure 3 shows the volume released from the Monte Cotugno reservoir for urban, industrial and

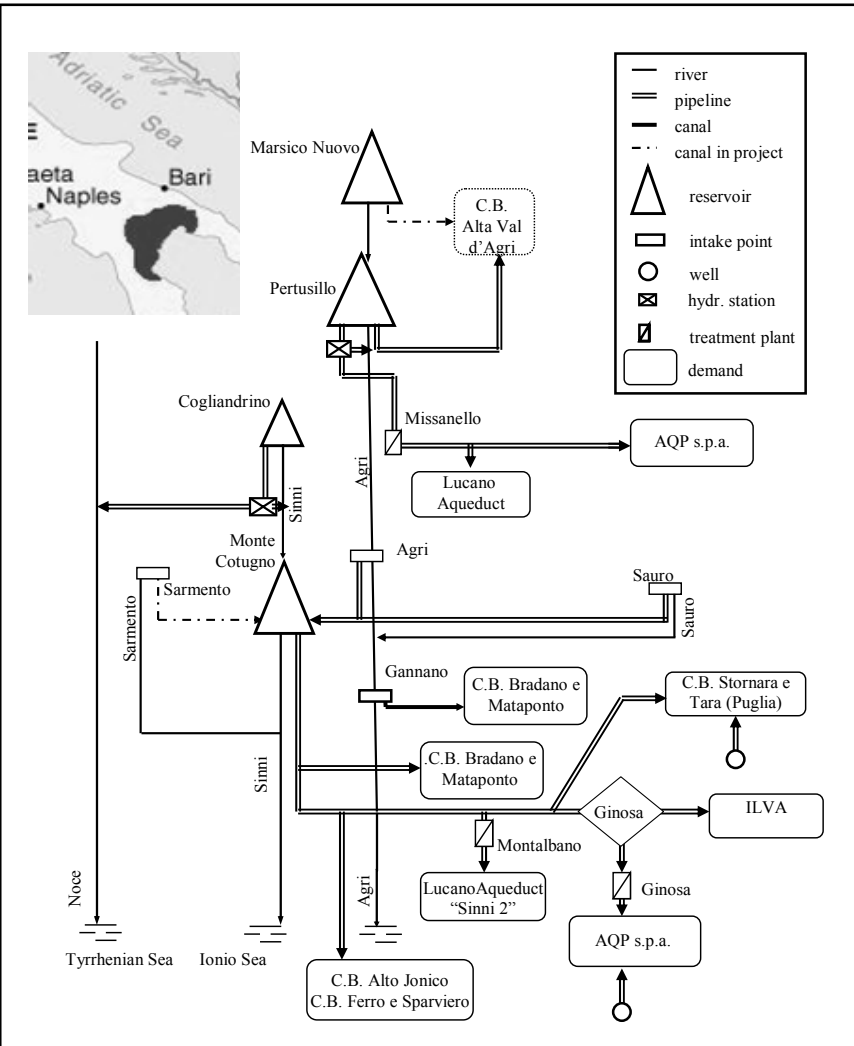

Figure 2. The Agri-Sinni system (PRIN, 2005) irrigation uses over the period 1993-2003. During one of the most serious drought occurrence (2001-2002) water restrictions, mainly imposed on irrigation consumption, were equal to $50 \%$ of the average supplies over the period 1993-2000. 
Numerous criteria could be used to summarize system performances (Hashimoto et al., 1982). Here, vulnerability (percentage value of maximum annual reduction on the total value of annual demand), time reliability (percentage value of the months in which reduction is less than predefined thresholds), volumetric reliability (percentage value of reduction on demand) have been used to quantify demand reductions. In this application to the Agri-Sinni system, mitigation measures have been finalized to preserve the complete satisfaction of priority demands for urban and industrial water requirements. Consequently, only the evaluation of system performances for irrigation use is reported when measures are implemented to face drought events.

Table 1. Statistical indexes of inflows in the period 1983-2005.

\begin{tabular}{lcccc}
\hline Stations & $\begin{array}{l}\text { Mean } \\
\left(\mathrm{m}^{3} \cdot 10^{6} / \text { year }\right)\end{array}$ & $\begin{array}{l}\text { Stand. Dev. } \\
\left(\mathrm{m}^{3} \cdot 10^{6} / \text { year }\right)\end{array}$ & $\begin{array}{l}\text { Max } \\
\left(\mathrm{m}^{3} \cdot 10^{6} / \text { year }\right)\end{array}$ & $\begin{array}{l}\text { Min } \\
\left(\mathrm{m}^{3} \cdot 10^{6} / \text { year }\right)\end{array}$ \\
\hline Pertusillo & 212.15 & 57.72 & 328.54 & 118.25 \\
Monte Cotugno & 277.60 & 106.61 & 494.14 & 118.45 \\
Cogliandrino & 89.76 & 32.12 & 147.13 & 33.95 \\
Marsico Nuovo & 7.82 & 3.04 & 12.91 & 2.53 \\
Gannano & 105.54 & 88.56 & 389.03 & 11.72 \\
Agri & 115.54 & 64.43 & 241.55 & 17.92 \\
Sauro & 50.46 & 25.50 & 101.31 & 11.93 \\
Sarmento & 84.10 & 38.79 & 162.06 & 26.42 \\
\hline
\end{tabular}

In a first phase, before applying the mixed simulation - optimization approach, a simulation-alone analysis using the WARGI-SIM module was carried out. System

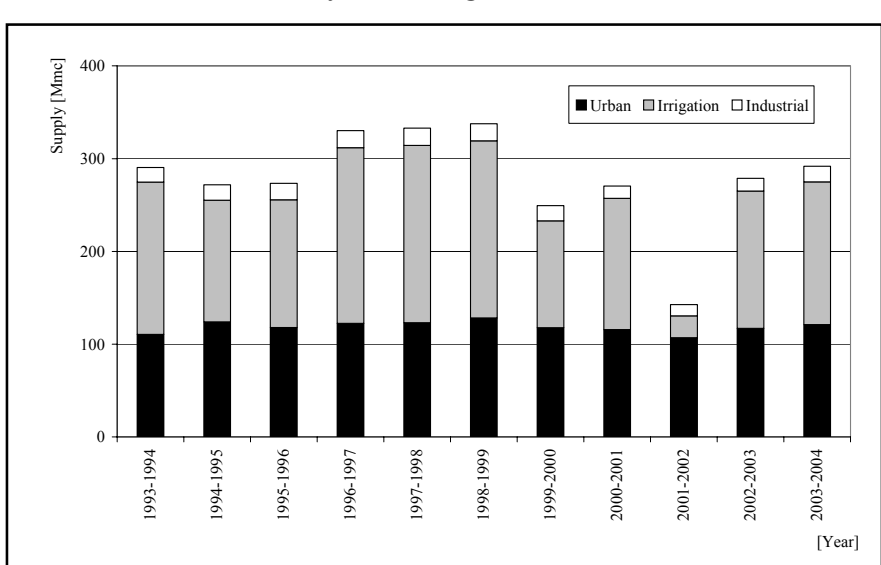

Figure 3. Historical releases from Monte Cotugno simulation considered the time horizon 1983-2005 and unit time period $\mathrm{t}$ equal to 1 month. Results provide an assessment of the system's capability to face water shortage situations when only a reactive approach is implemented in the AgriSinni system. Moreover this simulation analysis helps us assess the benefits of the preemptive measures defined by the mixed

optimization-simulation approach. In WARGI-SIM a reserved volume was defined in Monte Cotugno and Pertusillo to assure a full-satisfaction of urban and industrial demands. The reserved volume is a monthly function defined as:

$V_{\text {res }, t}=\sum_{j=t}^{\text {Oct }} k\left(R_{\text {urb }}+R_{\text {ind }}\right)_{j} \quad j=\{$ Mar, Apr, May, Jun, Jul, Aug, Sep $\}$

The reserved volumes considered in WARGI-SIM define a management policy in the AgriSinni that allocates resources for urban and industrial uses and reduced releases to irrigation use. The coefficient $k$ must be carefully defined to avoid unnecessary restrictions. The allocation policy requires the frequent implementation of reactive measures. 
Table 2 shows drought mitigation measures in the pro-active and reactive approach currently applied or planned by the water Authorities in the system. Additional measures have been also considered by the Authorities (e.g. construction of desalination plants or over-exploitation of aquifers) but not included in this study because of their uncertain fate.

Table 2. Drought mitigation measures in the Agri-Sinni.

\begin{tabular}{lll}
\hline Type of Measures & Pro-active approach $\left(z_{\tau}\right)$ & Reactive approach $\left(s_{t}\right)$ \\
\hline Supply Increase & Reallocation available resources & \\
& Use of additional sources & \\
Demand Reduction & Pricing & Temporary restriction \\
& Use of agronomic techniques & Percentage rationing
\end{tabular}

Mainly, reactive measures in the Agri-Sinni system consist of reductions in irrigation water availability by mandatory percentage restrictions in supply and temporary restriction limiting the irrigation of some annual crops. Thresholds of measures implementation were statically identified as follows:

1. When deficit is between $0 \%$ and $50 \%$ a temporary restriction is introduced and irrigation for perennial crops is assured to avoid damages to the trees;

2. When deficit exceeds $50 \%$ ration allocations as a percentage of use during normal period is created.

Results obtained by WARGI-SIM alone (Table 3) highlight the lack of effective measures in a planning strategy to increase system's reliability in the case of intensive drought. A maximum annual reduction of $80.3 \%$ and 5 years where reductions exceed $50 \%$ determine unsustainable stress conditions in the irrigation sector.

Table 3. Irrigation performance index values in the simulation and simulation-optimization approach.

\begin{tabular}{lccc}
\hline Index & SIM & OPT-SIM (A) & OPT-SIM (B) \\
\hline $\begin{array}{l}\text { Max annual reduction } \\
\text { (\% Demand) }\end{array}$ & 80.3 & 67.8 & 52.4 \\
$\begin{array}{l}\text { Time reliability } \\
(\% \text { Years) Reduction }=0 \%\end{array}$ & 43.5 & 34.8 & 65.2 \\
$\begin{array}{l}\text { Time reliability } \\
(\% \text { Years) Reduction } \leq 15 \%\end{array}$ & 65.2 & 56.5 & 95.6 \\
$\begin{array}{l}\text { Time reliability } \\
(\% \text { Years) Reduction } \leq 25 \%\end{array}$ & 69.6 & 65.2 & 95.6 \\
$\begin{array}{l}\text { Time reliability } \\
(\% \text { Years) Reduction } \leq 50 \%\end{array}$ & 78.3 & 87.0 & 95.6 \\
$\begin{array}{l}\text { Volumetric reliability } \\
(\% \text { Demand) }\end{array}$ & 79.8 & 84.0 & 85.6 \\
\hline
\end{tabular}

If the farmer has enough advance warning of drought before the irrigation season, he will have a number of drought management alternatives. Among these alternatives, he can choose between fully irrigating a lesser acreage, introducing water conservation practices and planting a more drought tolerant crop.

In the proposed approach, to mitigate the impact of these intensive drought in the predefined infrastructural configuration, water demand measures in a pro-active approach have been identified by WARGI-OPT based on synthetic series of monthly inflows $(\Delta=1$ year). There is a trade-off between criticality of synthetic series in WARGI-OPT and the effectiveness of drought mitigation measures in WARGI-SIM. Highly pessimistic series suggest unnecessary pre-emptive measures whereas over-optimistic series provide no 
useful information for the adoption of pre-emptive measures. According to the sensitivity analysis results, the $3^{\text {rd }}$ worst annual series of monthly inflows has been used by WARGIOPT to forecast system evolution 1 year ahead.

The pro-active approach applied to the Agri-Sinni includes measures that ration water demand for irrigation by pricing that influence the irrigation area and the use of less consumptive crops, and by using agronomic techniques that reduce consumption (Set A). Thresholds of pre-emptive measures implementation are dynamically defined by WARGIOPT based on the current storage volume at the synchronization period $\tau_{i}=$ April (the beginning of the irrigation period in the Mediterranean regions) in each system's reservoir and the $3^{\text {rd }}$ worst annual series of monthly inflows.

As shown in Figure 4, the Set A of pre-emptive measures is implemented in advance of the start of drought based on information provided by WARGI-OPT (e.g. demand reduction in a pro-active approach starts 2 years before the adoption of a reactive approach in 1999-2000 when a drought occurs). In the mixed optimizationsimulation approach, pre-

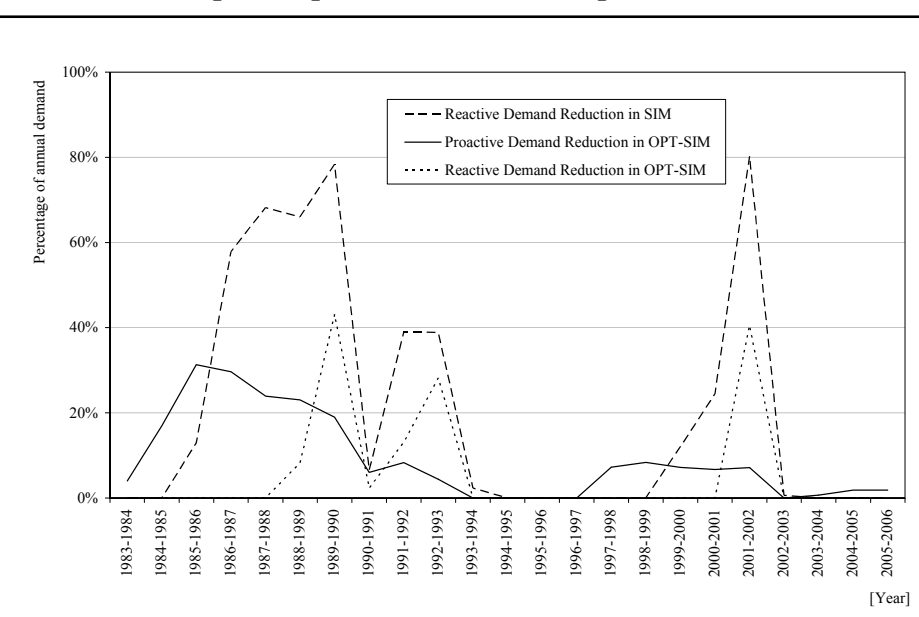

Figure 4. Temporal distribution of reduction measures in simulation (SIM) and in the mixed approach (OPT-SIM): the Set A case

emptive measures do not need the adoption in the simulation phase of any ration allocation and significantly reduces the implementation of temporary restrictions (Figure 4). At the cost of distributing reduction over a larger period, (temporal reliabilities at low thresholds in Table 3), the mixed optimization-simulation approach also reduces the total amount of reductions both in the reactive and proactive approach equalling $67.8 \%$ instead of $80.3 \%$ (WARGI-SIM alone) during one of the most serious scarcity period (2001-2002). Also a significant reduction of the reserved volume for urban and industrial demands is presented with the coefficient $k$ in (3), moving from 1 to 0.7 .

A second set of drought mitigation measures (Set B) in the pro-active approach has been also implemented with the aim of reducing the risk of water scarcity by modifying supplies. These water-supply measures include:

1. Wastewater treatment plants with a total capacity of $60 \cdot 10^{6} \mathrm{~m}^{3} / \mathrm{yr}$ serving irrigation demands;

2. Releases from the Cogliandrino reservoir serving different uses and a hydroelectric demand equalling $100 \cdot 10^{6} \mathrm{~m}^{3} / \mathrm{yr}$ (20\% in high priority).

In the pro-active approach, the volume exceeding the storage volume in the Cogliandrino reservoir to satisfy the hydroelectric demand, is transferred to the Monte Cotugno reservoir. In the event of forecasted scarcity events, WARGI-OPT increases water transfers during the spring season and saves water for future irrigation uses (Figure 5). 
As wastewater use and releases from Cogliandrino are coherently implemented in a planning strategy defined by WARGI -OPT, the mixed approach needs to adopt demand reduction measures in a reactive approach (e.g. temporary restriction measure) only during 2 serious water scarcity events (Figure 6) with lower economic and environmental

costs for the community than the simulation alone approach.

According to Table 3 the comparison between maximum annual values shows a significant reduction $(-35 \%)$ of the total restrictions when water supply measures of Set B are implemented by

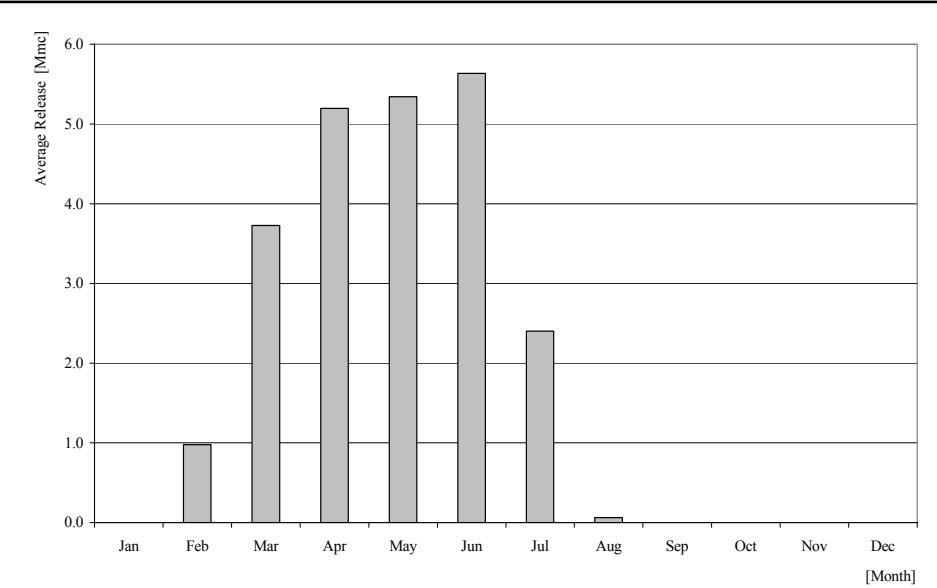

Figure 5. Mean monthly releases from the Cogliandrino reservoir as a water-supply measure in the pro-active approach

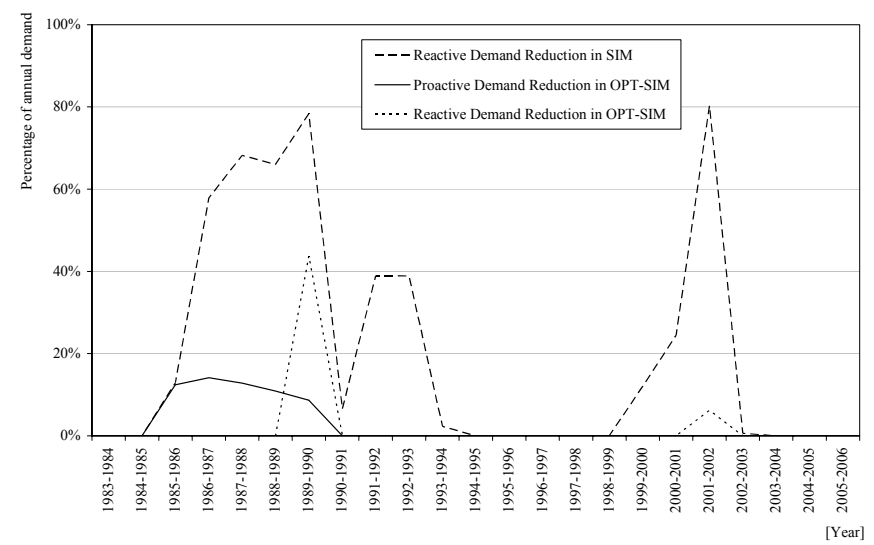

Figure 6. Temporal distribution of reduction measures in simulation (SIM) and in the mixed approach (OPT-SIM): the Set B case

the mixed optimization-simulation approach.

Also, it is to be noticed in the application results that demand-oriented measures in a proactive approach define a new reduced demand in the irrigation sector as these measures give to the farmer time enough to make the water adjustments

(Figure 7). The system evolution forecasting as defined by WARGI - OPT may provide the users with the flexibility needed to alter their water use from year to year. Choices of acreages and crops, and irrigation

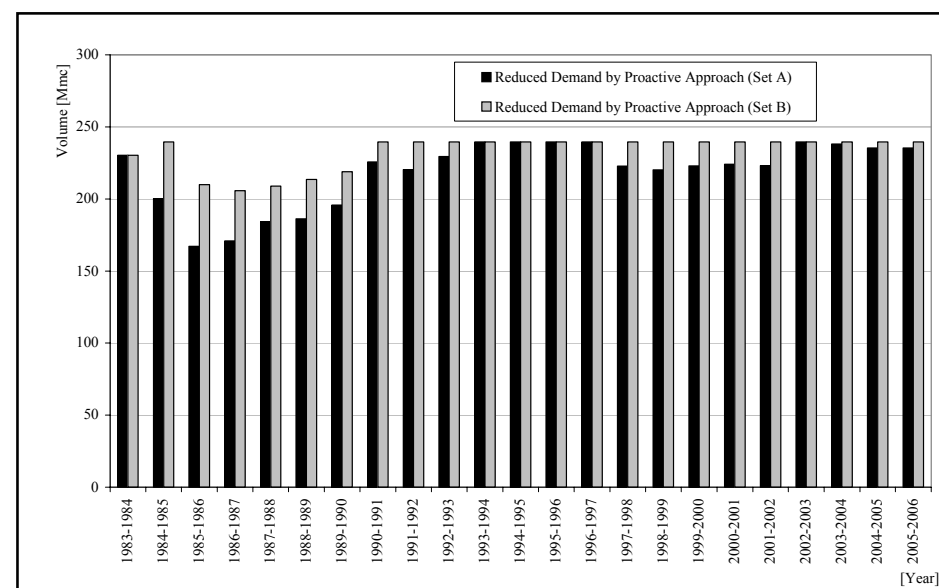

Figure 7. Reduced irrigation demand in the pro-active approach 
technologies are assumed to adjust over time based on the information provided by WARGI-OPT. As demand-oriented measures are planned in advance and agreed by all users, the selected demand reductions are potentially effective at reasonable loss in total benefit value for the users. Consequently, the evaluation of system performances for irrigation use could be better defined by using time and volumetric reliability, and vulnerability related to the new dynamic demand configuration of irrigation sector. Table 4 shows high reliability values both in Set A and Set B, particularly regarding high thresholds ( $15 \%$ of the reduced demand or higher). Also, the reduced volumetric reliability is close to $100 \%$.

Table 4. Irrigation performance index values based on reduced demand in the pro-active approach.

\begin{tabular}{lcc}
\hline $\begin{array}{l}\text { Index based on reduced } \\
\text { demand }\end{array}$ & OPT-SIM (A) & OPT-SIM (B) \\
\hline $\begin{array}{l}\text { Max annual reduction } \\
(\% \text { Reduced Demand) }\end{array}$ & 0.44 & 0.43 \\
$\begin{array}{l}\text { Reduced time reliability } \\
\text { (\% Years) Reduction }=0 \%\end{array}$ & 0.87 & 0.74 \\
$\begin{array}{l}\text { Reduced time reliability } \\
(\% \text { Years) Reduction } \leq 15 \%\end{array}$ & 0.96 & 0.87 \\
$\begin{array}{l}\text { Reduced time reliability } \\
(\% \text { Years) Reduction } \leq 25 \%\end{array}$ & 0.96 & 0.87 \\
$\begin{array}{l}\text { Reduced time reliability } \\
(\% \text { Years) Reduction } \leq 50 \%\end{array}$ & 1.00 & 1.00 \\
$\begin{array}{l}\text { Volumetric reliability } \\
(\% \text { Reduced Demand) }\end{array}$ & 0.94 & 0.93 \\
\hline
\end{tabular}

\section{CONCLUSIONS}

Although the implementation of reduction measures is frequently the focus of arguments among people involved, it is sometimes necessary to adopt in advance these measures even when they seem unnecessary. In these discussions, the main disagreements are related to the amount of measures to be taken in advance and the timing. Bad system evolution forecasting tends to encourage early and unnecessary restrictions, whereas good forecasting could delay the implementation of insufficient measures. The high economic and environmental costs of the crisis management have provided incentive to define new approaches to improve the effectiveness of mitigation measures and to minimize the impact of droughts. The application of the proposed mixed optimization-simulation approach to the Agri-Sinni water system in South Italy shows its usefulness in defining mitigation measures in a pro-active approach. The major advantage of this approach compared with traditional simulation approaches is the ability to dynamically adopt measures based on different scenarios of system evolution given by the optimization model. Also some improvements over the approach used in this application are possible. Promising improvements include the use of artificial intelligence techniques such as artificial neural network in the evaluation of some of the key aspects of this approach as the optimization time horizon or the reserved volume to assure full satisfaction in high priority demands.

\section{ACKNOWLEDGEMENTS}

This research was developed with the financial support of the Italian Ministry of Education, University and Research, under the PRIN 2005, "Decision Support Model in complex system management under shortage conditions", prot. 2005082390. The Authors wish to thank two anonymous reviewers for their useful comments on earlier draft.

\section{REFERENCES}

Hashimoto, T., D.P. Loucks and J.R. Stedinger, Reliability, Resiliency, and Vulnerability Criteria for Water Resource System Performance Evaluation, Water Resources Research, 18(1), 14-20, 1982. 
Hiew, K., J. Labadie and J. Scott, Optimal operational analysis of the Colorado-Big Thompson project. In: Computerized decision support systems for water managers, Labadie et al. (eds), Reston, Va., 632-646, 1989.

James, L.D., and R.R. Lee, Economics of water resources planning, McGraw-Hill, 1971.

Lund, J.R., Derived estimation of willingness to pay to avoid probabilistic shortage, Water Resources Research, 31(5), 1367-1372, 1995.

PRIN, Decision Support Model in complex system management under shortage conditions, prot. 2005082390, Italian Ministry of Education, University and Research, 2005.

Sechi, G.M. and A. Sulis, Mixed simulation-optimization technique for complex water resources systems analysis under drought conditions, Chapter 11. In: Methods and Tools for Drought Analysis and Management, Rossi, G., T. Vega, and B. Bonaccorso (eds), Springer, 217-237, 2007.

Yevjevich, V., W.A. Hall and J.D. Salas, Proc. Conference on Drought Research Needs, Water Resources Publications, Fort Collins, 1978. 